\title{
Contribuições do PIBID Interdisciplinar de Licenciatura em Computação e Pedagogia na Escola
}

\author{
Poliana Santos de Queiroz, Higor R. Monteiro Santos \\ Universidade de Pernambuco, Campus Garanhuns (UPE) \\ CEP 55.294-902 - Garanhuns - PE - Brasil \\ poliana.santos.queiroz@gmail.com, higor.monteiro@upe.br
}

\begin{abstract}
The purpose of this paper is to report on the activities and contributions of the Programa Institucional de Bolsas de Iniciação à Docência (PIBID) carried out by the Undergraduate Courses in Computing and Pedagogy of the University of <omitted for review>. In view of this, the perspectives of the students of the university, supervisors and students of the School. The activities took place in the 6th, 7th and 8th grades of Elementary School throughout 2016. The results reinforce that the participation of the graduates in the PIBID contributes significantly in the teaching and learning process emphasizing that the results were higher than the expectations in the planning from the project.
\end{abstract}

Resumo. Este artigo tem como objetivo relatar as atividades e contribuições do Programa Institucional de Bolsas de Iniciação à Docência (PIBID) realizado pelos cursos de Licenciatura em Computação e Pedagogia da Universidade de $<$ omitido para revisão>. Diante disso, foi levado em consideração as perspectivas dos licenciandos bolsistas, professores supervisores e alunos da Escola <omitido para revisão $>$. A atuação aconteceu nas turmas do $6^{\circ}, 7^{\circ}$ e $8^{\circ}$ anos do Ensino Fundamental ao longo do ano de 2016. Os resultados reforçam que a participação dos licenciandos no PIBID contribui significativamente no processo de ensino e aprendizagem destacando que os resultados foram superiores às expectativas no planejamento do projeto.

\section{Introdução}

No dia a dia, lida-se com vários tipos de tecnologias que transformam as relações entre as gerações através do acesso à informação e do uso do conhecimento nas interações. Este contexto de influências acarretou uma nova forma de participação da/na sociedade. Toda essa transformação que se estende aos mais variados equipamentos tecnológicos foi adquirindo seu espaço a partir do conhecimento do homem e da necessidade de tais instrumentos fazerem parte do processo de trabalho, o que facilitaria parte das demandas operacionais [BRITO 2008].

Diante de tamanha transformação, cresce a demanda e as exigências no âmbito da educação. Na contemporaneidade, o aluno já nasce no mundo das Tecnologias Digitais de Informação e Comunicação (TDICs) e no decorrer de sua vivência aprende como utilizar as tecnologias de acordo com seus interesses, com e sem a presença de um professor. Sendo assim, os alunos adquirem e promovem aprendizagens em espaços virtuais que vão além dos muros da escola. O contexto socioeconômico atual está marcado por contínuas transformações que, em grande parte, procedem da evolução e difusão de novas tecnologias de informação e comunicação, das inovações nas 
tecnologias em produtos e produção e da geração e difusão do conhecimento. É nesse contexto que se amadurece cada vez mais o debate sobre o uso de tecnologia na educação e percebe-se sua necessidade diante dos problemas atuais e daqueles que estão por vir.

Atualmente, as discussões centram-se em como promover bom uso da tecnologia e como formar professores para mediar esse uso. Sendo assim, pensar a educação na atualidade envolve pensar em novas formas de ensinar, aprender e desenvolver competências percebendo-se no mundo. Em meio a tantas modificações no acesso e na utilização das tecnologias, a escola e o professor vêm sendo forçados a reexaminar suas práticas, a fim de (re)significar sua atuação [MORAN 2000].

A integração dentro de espaços escolares tem fomentado discussões sobre novas práticas e métodos no processo de ensino e aprendizagem [FERREIRA et al. 2015]. O Model Curriculum K-12 Computer Science ${ }^{l}$, por exemplo, destaca que a maioria das profissões do século XXI exige uma compreensão da Ciência da Computação. Profissionais de arte, entretenimento, educação, comunicação, saúde, entre outros, precisam ter conhecimentos da Computação, enquanto ciência, na busca por soluções de problemas de áreas diversas, bem como na construção dessas soluções [FRANÇA et al. 2012].

Com isso, além da integração das tecnologias digitais (computadores, celulares, tablets, etc.), torna-se relevante para os alunos das séries iniciais, o ensino de conceitos fundamentais da Ciência da Computação [NUNES 2011]. Esses conceitos propiciam o desenvolvimento de habilidades que são exigidas no mundo atual, tais como, pensamento computacional, criatividade e raciocínio lógico. Habilidades estas que auxiliam na resolução de qualquer tipo de problema [NETO, SANTOS E SANTOS 2015].

No atual contexto educacional, é necessário repensar o papel do docente no que concerne o uso das TDICs como ferramenta pedagógica [BRANDÃO, SELVA E COUTINHO 2006]. Para tanto, a formação do professor deve estar elencada sobre as possibilidades e maneiras de se utilizar tais recursos em prol de uma prática pedagógica efetiva. Como constituinte das políticas públicas educacionais, o Programa Institucional de Bolsas de Iniciação à Docência (PIBID) é uma iniciativa da Coordenação de Aperfeiçoamento de Pessoal de Nível Superior (CAPES) que tem como objetivo a elevação da qualidade das ações acadêmicas voltadas à formação inicial de professores nos cursos de licenciatura das instituições de educação superior. Além disso, o programa visa também proporcionar aos futuros professores participação em experiências metodológicas, tecnológicas e práticas docentes de caráter inovador e interdisciplinar e que busquem a superação de problemas identificados no processo de ensinoaprendizagem [CAPES, 2008].

Na Universidade <omitido para revisão $>$, o programa está em vigor desde de 2011 em seus quatro campi. Sua estrutura possui subprojetos em áreas específicas e subprojetos interdisciplinares com a colaboração de várias áreas. Aquilo que se é desenvolvido em cada subprojeto leva em consideração especificidades do contexto no qual a escola está inserida e o Projeto Político Pedagógico (PPP) para que assim o resultado do agir tenha significação.

Nesse contexto, o objetivo principal deste artigo caracteriza-se em relatar, analisar e discutir os resultados obtidos de um subprojeto interdisciplinar com a integração de licenciandos de Computação e Pedagogia no ano de 2016. Os resultados apresentados neste trabalho foram coletados na Escola <omitido para revisão $>$. As situações

\footnotetext{
${ }^{1}$ Ver em https://goo.gl/4kAE1b
} 
VI Congresso Brasileiro de Informática na Educação (CBIE 2017)

Anais do XXIII Workshop de Informática na Escola (WIE 2017)

pedagógicas ligadas a essa experiência foram desenvolvidas em turmas do $6^{\circ}, 7^{\circ}$ e $8^{\circ}$ anos do Ensino Fundamental.

\section{Trabalhos Relacionados}

A Computação, entendida como conhecimentos a respeito de computadores, sistemas de computação e suas aplicações, abrange aspectos teóricos, experimentais de modelagem e de projeto. Os cursos desta área têm a Computação como área fim ou de especialidade, ou como área meio de atuação multidisciplinar. No que se refere ao ensino de Computação na educação básica, o ponto de partida é a sua concepção. Muito se confunde sobre o que é informática e Computação. Segundo Nunes [2011], a informática é o uso de aplicativos como por exemplo Word, Excel, Power Point. Por sua vez, Computação é a ciência do desenvolvimento e implementação de softwares.

De acordo com França et al. [2013] a Computação "pode contribuir, de maneira interdisciplinar, na busca de soluções de problemas diversos, através da disseminação do chamado pensamento computacional". Onde o pensamento computacional é um processo cognitivo já utilizado por seres humanos para encontrar solução para uma situação difícil. Contudo, o currículo das escolas brasileiras não contempla a Ciência da Computação como componente curricular fixo. Para a Sociedade Brasileira de Computação (SBC), a Computação deve ser tratada como qualquer outra ciência que auxilie diretamente no desenvolvimento do educando e como consequência, na evolução do país.

Nesse contexto, observa-se que a atuação de Licenciados em Computação é uma oportunidade para inserir os conceitos e práticas de Computação, enquanto ciência, na escola. Segundo Nunes [2011], são profissionais capazes de lecionar a Computação de forma lúdica e atrativa aos alunos de diferentes níveis educacionais. Como por exemplo, é possível desenvolver tecnologias capazes de ser usadas como mecanismo de apoio aos processos de ensino e aprendizagem das diferentes disciplinas que compõe o currículo básico nacional. Com o objetivo de posicionar esta experiência frente a outras já existentes na literatura, nesta seção são listados trabalhos direcionados na tentativa de inserir na educação básica os conceitos e práticas relacionadas ao ensino de Computação.

Sousa [2013] relata uma experiência adquirida em um curso de Introdução à Algoritmos no Ensino Médio em uma escola pública da região metropolitana de Belém Pará, oferecido pelos alunos do curso de Licenciatura em Computação através do PIBID. O curso teve como finalidade inserir o raciocínio lógico utilizando algoritmos escritos em uma linguagem de programação chamada Portugol. Tendo como objetivo avaliar o grau de receptividade dos alunos do ensino médio e também de mediar a aprendizagem e a vivência prática do ensino de lógica e algoritmos pelos alunos da Licenciatura. $\mathrm{O}$ curso foi oferecido em contra turno e teve duração de 40 horas. Seus principais resultados foram a motivação para fazer um curso superior na área de computação pelos alunos que concluíram o curso.

Friedrich et al. [2012] relatam experiências obtidas durante um processo de ensino de lógica de programação para crianças de sete a dez anos de idade, como meio auxiliar de ensino, o programa Logo e o projeto Lego Mindstorms. Através dos resultados os autores mostram que todas as atividades vivenciadas foram realizadas com sucesso pelas crianças. Suas principais contribuições foram o de plantar uma semente sobre o ensino de lógica de programação para crianças do Ensino Fundamental da rede pública.

Marques et al. [2011] oportunizou aos alunos do ensino médio da região do Vale do Mamanguape na Paraíba a oportunidade de alcançar competências referentes ao 
desenvolvimento de jogos digitais através da linguagem de programação Python. A escolha de tal linguagem foi defendida pelos autores por simplificar o aprendizado de algoritmos e programação. Os principais benefícios foram os indícios de que ensinar programação no ensino médio é algo interessante e que o uso de jogos pode servir de fator motivacional forte e o levantamento de algumas práticas para o ensino de programação que podem contribuir para uma aprendizagem de sucesso.

Finizola et al. [2014] aplicaram um curso com a ferramenta App Inventor aos alunos do Ensino Médio pertencentes ao $1^{\circ}$ ano de uma escola pública estadual da cidade de Rio Tinto - PB. Os alunos puderam treinar a programação criando aplicativos que poderiam ser executados em seus próprios dispositivos móveis para, então, terem a real noção de como os comandos reagem à forma como são dispostos.

Silva et al. [2011] relatam uma experiência relevante que consistiu em ensinar conceitos de Ciência da Computação no ensino médio introduzindo noções de algoritmos utilizando música e a robótica. O conceito de algoritmo foi trabalhado com o instrumento musical pandeiro, onde a música foi associada com a ideia de executar um conjunto de instruções para reproduzir a saída desejada, que seria a melodia. Assim, a sequência de passos para executar a melodia representou as instruções e passos que um algoritmo possui. Para associar com algoritmos computacionais foi utilizada a robótica com o Robô Lego Mindstorms NXT.

Queiroz et al. [2016] relatam uma experiência no PIBID de licenciandos de Computação com uma turma do $6^{\circ}$ ano do Ensino Fundamental de uma escola pública da cidade de Garanhuns- PE. Os pibidianos desenvolveram junto aos alunos práticas e conceitos de Computação enquanto ciência, sendo possível a vivência de novos processos formativos.

Ao analisar esses trabalhos relacionados, pode-se afirmar que o PIBID interdisciplinar de Licenciatura em Computação e Pedagogia da Universidade <omitido para revisão $>$ teve como diferencial uma prática pedagógica sistêmica e dinâmica vinculada aos campos de aprendizagem. Além de pensar o planejamento ligado ao contexto do aluno, os licenciandos envolvidos utilizaram novas ferramentas e metodologias para disseminar a Computação na Educação básica. De início, na aplicação de novas estratégias para desenvolver atividades de Computação Desplugadas e por seguinte com a utilização de plataformas de programação como SuperLogo e Scratch e objetos de aprendizagem eletrônico. Além disso, foi estimulada a criação de histórias em quadrinhos no HagáQuê e utilização de jogos, como o Enigma frações.

\section{Metodologia}

Com a intenção de alcançar os objetivos, o projeto interdisciplinar do PIBID foi realizado de acordo com as seguintes etapas:

A. Diagnose: consistiu no conhecimento do Projeto Político Pedagógico (PPP) na observação do ambiente escolar para descrever e identificar o meio no qual se desenvolveu o projeto como os aspectos culturais característicos da comunidade na qual os licenciandos foram inseridos e elaboração e aplicação do questionário ${ }^{2}$. $\mathrm{O}$ mesmo foi elaborado levando em consideração as variáveis existentes, no ambiente no qual o aluno estava inserido servindo de guia para elaboração de situações didáticas ligadas ao contexto dos alunos;

\footnotetext{
${ }^{2}$ Questionário de Diagnose - https://goo.gl/7WZN4j
} 
B. Estrutura didática: com base nas observações feitas no ambiente escolar e na análise dos questionários respondidos pelos alunos do $6^{\circ}, 7^{\circ}$ e $8^{\circ}$ anos, foi elaborada uma estrutura didática, onde juntamente com o coordenador de área e três supervisores foi pensado e planejado como aconteceriam as atividades de pesquisa e formulação de problemas levantados através do questionário e das observações feitas pelos pibidianos no ambiente escolar;

C. Elaboração de situações didáticas: nessa etapa, foi feita a escolha de atividades desplugadas e dos softwares. Em seguida, foi elaborada a metodologia de trabalho para se desenvolver de forma interdisciplinar. Foram escolhidas atividades desplugadas do code.org ${ }^{3}$, uma organização sem fins lucrativos cujo objetivo é divulgar e ensinar programação a pessoas de todas as idades. Os softwares escolhidos foram: HagaQuê $\hat{e}^{4}$ um editor de histórias em quadrinhos com um banco de imagens com os diversos componentes para a construção de uma história e vários recursos de edição; Enigmafrações ${ }^{5}$, um jogo de matemática para o ensino fundamental cujo objetivo é resolver cálculos de frações em forma de enigma para passar de fase; SuperLogo ${ }^{6}$, uma linguagem de programação utilizada para automação e controle de dispositivos robóticos; Scratch ${ }^{7}$, uma linguagem de programação gráfica desenvolvida especialmente para crianças;

D. Aplicação do projeto: entre agosto e dezembro de 2016 trabalhou-se Escola Municipal <omitido para revisão> com 29 alunos do $6^{\circ}, 28$ alunos do $7^{\circ}$ e 28 alunos do $8^{\circ}$ ano do ensino fundamental. Cada equipe se dividiu e atuou nas diferentes turmas de forma interdisciplinar de acordo com um cronograma elaborado juntamente com os supervisores respeitando o calendário da escola e o horário do professor colaborador, sendo este o responsável por mediar a disciplina em sala de aula;

E. Acompanhamento: encontros eram realizados semanalmente com o coordenador com a intenção de socializar todas as atividades desenvolvidas. Além disso, os supervisores se reuniam com os pibidianos com a intenção de avaliar o desempenho e oferecer feedbacks de melhoria, bem como um suporte pedagógico necessário no processo de ensino e aprendizagem. Esse desempenho era avaliado mediante alguns aspectos pedagógicos e indicadores de atividades docentes que foram criados pelos licenciandos de Pedagogia ${ }^{8}$. Segundo Schö [1983], esse tipo de reflexão permite que os professores se assumam como investigadores da própria prática docente;

F. Criação de um objeto de aprendizagem (OA): os pibidianos também tiveram como atividade o planejamento e desenvolvimento de objetos de aprendizagem eletrônico levando em consideração alguns critérios no desenvolvimento do jogo. Tais como: Documentação (Game Design) que diz respeito ao material que acompanha o OA e que contém informações quanto a faixa etária, conteúdos, manual de uso; Currículo que refere-se ao conteúdo previsto para o desenvolvimento de atividades escolares com a ferramenta; Aspectos didáticos, subdivididos em clareza dos conteúdos, assimilação e acomodação, recursos motivacionais, avaliação do aprendizado, carga educacional e tratamento das dificuldades e tratamento do erro. Após seu término, os OAs desenvolvidos foram disponibilizados para que os professores utilizassem em suas aulas;

\footnotetext{
${ }^{3}$ Site do Corde.org -https://code.org/

${ }^{4}$ Site do HagaQuê - http://www.nied unicamp.br/?q=content/hag\%C3\%A1qu\%C3\%AA

${ }^{5}$ Site do Enigmafrações - https://novaescola.org.br/arquivo/jogos/enigma-fracoes/

${ }^{6}$ Site do Superlogo - http://projetologo.webs.com/slogo.html

${ }^{7}$ Site do Scratch - https://scratch.mit.edu/

${ }^{8}$ Aspectos pedagógicos e indicadores de atividades docentes - https://goo.gl/yHDK8h
} 
G. Avaliação dos resultados: ao fim do projeto, aplicou-se outro questionário ${ }^{9}$ com os alunos que participaram do desenvolvimento do projeto com a intenção de verificar se a utilização dos softwares educativos auxiliou na compreensão dos assuntos trabalhado nas disciplinas e a satisfação deles quanto ao ensino dos conceitos de Computação. Além disso, realizou-se uma entrevista de cunho qualitativo com intuito de verificar, sob o ponto de vista dos pibidianos e professores, as situações vivenciadas através da aplicação do projeto;

H. Elaboração de Relatório Técnico de Conclusão: as equipes se dividiram e relataram as atividades desenvolvidas no intuito de documentar o desenvolvimento das atividades vivenciadas desde de a primeira visita até a última no ambiente escolar onde as atividades planejadas foram desenvolvidas.

\section{Resultados}

Conforme descrito na seção anterior, a primeira etapa do projeto foi a realização de uma diagnose. Nesse aspecto, apresentou-se num primeiro momento para os alunos do $6^{\circ}, 7^{\circ}$ e $8^{\circ}$ anos os conceitos sobre: Computação, Informática, Pensamento Computacional e seus quatro pilares (Decomposição, Algoritmo, Abstração e Reconhecimento de Padrões). Nessa etapa, abordou-se fundamentos introdutórios da Computação, como evolução do computador, números binários, bits e bytes, hardware, software e processamento de dados. Um dos intuitos desta etapa foi apresentar aos alunos, mesmo que de forma introdutória, fundamentos básicos da Computação.

Como atividade inicial para se trabalhar o conceito de algoritmo, os alunos eram chamados ao quadro para escrever um passo a passo de algumas atividades que realizavam diariamente. A Figura 1 demonstra uma aluna escrevendo um algoritmo no quadro relacionado a atividade diária de acordar, ir à escola e voltar para sua casa.

As atividades de Computação Desplugadas foram escolhidas do code.org. Dentre as atividades escolhidas estão o Happy Maps, onde os alunos criaram algoritmos simples para mover um personagem por um labirinto; Simulando um Robô, uma atividade realizada no pátio da escola onde os alunos criavam comandos para chegar até outro aluno que simulava o robô; Algoritmo do Avião de Papel, nesta atividade os alunos elaboraram diferentes sequências para se conseguir montar um avião de papel.

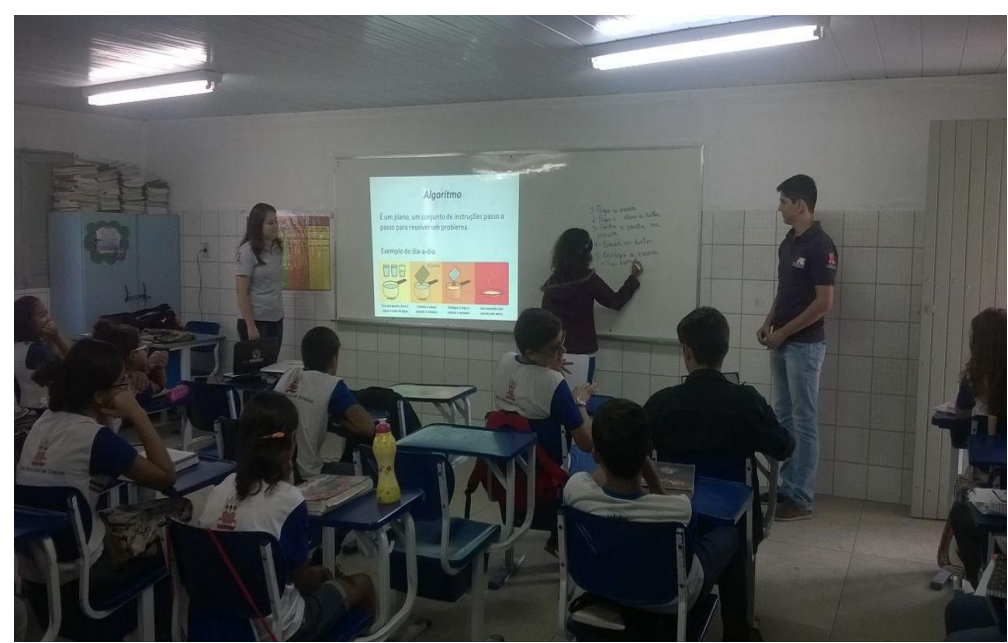

Figura 1: Aluna produzindo algoritmo no quadro

\footnotetext{
${ }^{9}$ Questionário de avaliação final - https://goo.gl/xAghdn
} 
Todo o trabalho foi desenvolvido de forma interdisciplinar com a integração de diferentes disciplinas, conteúdos e abordagens. Escolheu-se o HagaQuê, para trabalhar com o $7^{\circ}$ ano, o professor colaborador estava a desenvolver atividades relacionadas a produção de texto, gêneros textuais e gramática. Diante disso, trabalhou-se a usabilidade do mesmo na construção de história em quadrinhos dentro da disciplina de Português.

O Enigma frações foi vivenciado no $6^{\circ}$ ano, onde o professor colaborador estava a ensinar aos alunos os conceitos de frações. Para auxiliar no entendimento e resolução desse assunto, foram apresentados enigmas em forma de frações propostos no jogo. Também no $6^{\circ}$ ano foi trabalhado com a versão 3.0 do SuperLogo, a usabilidade do mesmo não aconteceu somente no auxílio ao ensino de lógica de programação, mas foi possível trabalhar com os mesmo o desenho de figuras geométricas e no apoio ao desenvolvimento do conteúdo de ângulos.

O Scratch foi trabalhado no $6^{\circ}$ e no $8^{\circ}$ ano, dividiu-se a vivência desse software em dois momentos. De início, abordou-se conceitos teóricos de programação, onde apresentou-se para os alunos a programação em blocos, em que apresentou alguns comandos básicos e os recursos que podem ser usados na criação de jogos ou animações dentro da ferramenta Scratch. Nesse momento, os alunos foram motivados a descobrir outras funcionalidades da ferramenta de forma autônoma e, em seguida, pediu-se que os alunos criassem animações e jogos de acordo com o conteúdo que estava sendo trabalhado pelo professor colaborador.

O que mais chamou atenção no desenvolvimento de atividades com o Scratch foi a postura criativa e autônoma que os alunos tomaram quando ao se depararem com os conflitos na organização da estrutura lógica dos blocos frente as animações que estavam construindo. Após cada aula, os licenciandos de Computação e Pedagogia se reuniam com os supervisores com o objetivo de avaliar o desempenho da aula de acordo com os indicadores que foram elaborados pelos licenciandos de Pedagogia participantes do projeto interdisciplinar. Nesse momento, eram discutidas formas de melhorar a ação docente, enxergar as potencialidades e limitações de diferentes abordagens, estratégias, metodologias e atividades mais eficientes, transformadoras, significativas e humanistas.

Além da aplicação desses softwares já existentes, novos objetos de aprendizagem eletrônicos foram desenvolvidos pelos alunos e pelos licenciandos. Esta atividade corresponde a etapa de Criação de um Objeto de Aprendizagem. Após o ensino dos conceitos de algoritmos e a utilização da ferramenta Scratch, os licenciandos em Computação solicitaram aos alunos que desenvolvessem aplicações que estivessem relacionadas ao conteúdo que estava sendo trabalhado na disciplina. Dessa forma, os alunos puderam colocar em prática os conhecimentos adquiridos nas disciplinas correspondentes (Português, Matemática e Geografia) e os de Computação, como o raciocínio lógico, criatividade e pensamento computacional.

Ao término das atividades, foram coletadas algumas informações através da aplicação de um questionário. Foi possível evidenciar o impacto positivo que a atuação dos pibidianos de Computação e Pedagogia causou aos 85 alunos do ensino fundamental que participaram da experiência do projeto. Diante dos resultados, verificou-se que 76 alunos afirmaram que a utilização dos computadores com a mediação dos licenciandos de Computação melhorou na compreensão do conteúdo abordado em sala de aula. Viuse que 84 alunos afirmaram que o professor deveria utilizar o laboratório de informática mais vezes para mediar conteúdos. 81 alunos responderam que voltariam a usar a ferramenta Scratch e 65 alunos conseguiram diferenciar claramente o conceito de informática e Computação. 
Com a intenção de coletar a opinião dos licenciandos a respeito das contribuições do PIBID de Computação referente às suas experiências vivenciadas, foram realizadas entrevistas semiestruturadas após o término do projeto, em dezembro de 2016. Ressaltase que os nomes dos entrevistados foram omitidos intencionalmente por questões de privacidade.

Conforme o Licenciando 1, "o PIBID de Computação contribuiu imensamente e de forma positiva. Foi através dele que tive a oportunidade de estar em sala de aula e vivenciando a realidade de muitas escolas. E foi através do PIBID que pude ver se queria ou não estar em uma sala de aula futuramente. Contribui não só falando na parte profissional, mas em mim como pessoa".

Por sua vez, o Licenciando 2 afirmou que "o PIBID de Computação trouxe contribuições na experiência da docência, encarando diversas realidades. Além do mais, me fez pôr em prática o ensino de computação na educação básica, fazendo com que eu corrigisse meus erros e aprimorasse meus acertos".

Ao se depararem com um grupo de alunos de Computação e Pedagogia, os supervisores ficaram curiosos para saber como licenciandos de Computação e Pedagogia poderiam trabalhar conteúdos de Computação de forma interdisciplinar sem perder a qualidade da aula. A expectativa para saber como se daria o desenvolvimento do projeto fez com que os supervisores estivessem sempre presentes em sala de aula. Nessa perspectiva, um dos supervisores relatou o que achou da atuação do PIBID interdisciplinar de Computação e suas contribuições.

Conforme o Supervisor 1, "O trabalho com os alunos do projeto interdisciplinar de Computação e Pedagogia foi muito proveitoso. O planejamento e a inovação nos métodos de trabalho trouxeram muito aprendizado e incentivo tanto para os alunos quanto para os professores e licenciandos de outras áreas". Por sua vez o supervisor 2, afirmou que "Enquanto supervisora do PIBID de Computação, posso dizer que houve troca de experiências e enriquecimento dos saberes, bem como ações positivas e resultados acima das expectativas"

Na região de <omitido para revisão>, a Computação chegou até a escola básica por meio do PIBID. Com a interação dos licenciados com os alunos da escola, foi possível perceber mudanças de atitudes nesses alunos. Mudanças essas relatadas por eles nas falas que seguem.

O aluno 1, "Os pibidianos de Computação usaram a criatividade para explicar os assuntos, deu para aprender o conteúdo, principalmente quando utilizaram jogos". Por sua vez, o aluno 2 afirmou que: "O PIBID de Computação é diferente dos outros, os assuntos trabalhados com os professores de Computação me ajudaram aprender o conteúdo de Português e a resolver problemas, ficou mais fácil”.

Analisando as falas referente ao trabalho que foi desenvolvido em 2016, percebese que foi possível estabelecer um diálogo entre licenciando de Computação e aluno e entre escola e universidade. É notável o caráter inovador das aulas ministradas e as possibilidades de se trabalhar Computação junto a outras áreas do conhecimento.

\section{Considerações Finais}

O PIBID tem se demonstrado um programa bastante efetivo no cenário nacional para a melhoria tanto da formação dos licenciandos como também das próprias escolas que recebem o programa [CAPES, 2008]. Nesse contexto, este artigo relatou mais uma experiência da interação Universidade-Escola. Foi evidenciado a estreita relação entre os 
licenciandos, orientados por um coordenador professor da Universidade, juntamente com professores supervisores e alunos das escolas com a intenção de ensinar os conceitos e práticas da Computação, enquanto ciência, de forma interdisciplinar.

De acordo com os resultados obtidos e relatados na Seção 4, é possível perceber que todos os objetivos propostos foram alcançados. Foram observadas as experiências e contribuições de todos os envolvidos: licenciandos, supervisores e alunos da escola. A partir da vivência de tal projeto, buscou-se criar novas oportunidades educacionais. Pensando assim a ação docente mediada também a partir de conceitos de Computação para uma sociedade em constante mudança.

Além de contribuir para a formação docente, os trabalhos desenvolvidos se destacam pela disseminação do ensino de Computação de forma interdisciplinar na Educação Básica. Foi possível trabalhar em conjunto com as disciplinas de Português, Matemática e Geografia. Além disso, foram desenvolvidos objetos de aprendizagem eletrônicos para ensino e aprendizagem dos conteúdos que estavam sendo trabalhados pelos professores. Esses OAs foram disponibilizados para que os próprios professores os reutilizassem em aulas futuras. Por fim, é importante destacar a excelente aceitação e envolvimento nas atividades por meio dos alunos e supervisores da escola.

Como oportunidades de trabalhos futuros, destacam-se:

- Utilizar a mesma metodologia aqui relatada para trabalhar conceitos de Computação junto a outras disciplinas da escola, tais como, história, física e química;

- Promover competições entre as turmas com desenvolvimento de softwares educativos;

- Realizar uma feira de Computação demonstrando os resultados alcançados pelos alunos e possibilidades tecnológicas.

\section{Referências}

Brandão, A, Selva, A, Coutinho, M. (2006) "O trabalho com projetos didáticos: integrando a leitura e a produção de textos". Belo Horizonte: Autêntica.

Brito, G. “Educação e Novas Tecnologias: Um repensar". (2011) 2. Ed. rev., atual. E ampl. Curitiba: Ibpex, 2008. 139 p.

Capes. "PIBID- Programa Institucional de Bolsas de Iniciação à Docência". (2008). Disponível em:<http://www.capes.gov.br/educacao-basica/capespibid/pibid $>$. Acesso em: 11 fev. 2017.

Ferreira, M; Lima, J; Santos, H, Oliveira, E; Nascimento, J. (2015) “Computação para Ensino Médio na Modalidade Semipresencial: Uma Experiência da Disciplina de Estágio Supervisionado". In: Workshop de Informática na Educação (WIE).

Finizola, A. Raposo, E, Pereira, M; Gomes, W; Araújo, A; Souza, F. (2014). “O ensino de programação para dispositivos móveis utilizando o MIT-App Inventor com alunos do ensino médio", Em: XX WIE - Workshop de Informática na Escola.

França, R; Silva, W; Amaral, H (2012) "Ensino de Ciência da Computação na Educação Básica: Experiências, Desafios e Possibilidades”. In: XX Workshop sobre Educação em Computação (WEI). 
VI Congresso Brasileiro de Informática na Educação (CBIE 2017)

Anais do XXIII Workshop de Informática na Escola (WIE 2017)

França, R.; Amaral, H. (2013) "Proposta metodológica de ensino e avaliação para o desenvolvimento do pensamento computacional com o uso do scratch". Anais do Workshop de Informática na Escola, v. 1, n. 1, p. 179.

Friedrich, Ronaldo Vaz; Santos, Daniela Scherer; Keller, Rodrigo dos Santos; Puntel, Márcio Daniel; Biasoli, Daniel. (2012) "Proposta Metodológica para a Inserção ao Ensino de Lógica de Programação com Logo e Lego Mindstorms". Anais do Simpósio Brasileiro de Informática na Educação, v. 23, n. 1.

Marques, D; Costa, L; Silva, M; Rebouças, A. (2011) “Atraindo Alunos do Ensino Médio para a Computação: Uma Experiência Prática de Introdução a Programação utilizando Jogos e Python", Em: XVII WIE - Workshop de Informática na Escola, Aracajú, Anais do XXII Simpósio Brasileiro de Informática na Educação.

Moran, José Manuel. (2000) “A integração das tecnologias na educação. Artigo publicado na revista Informática na Educação: Teoria \& Prática". Porto Alegre, vol. 3, n.1 UFRGS. Programa de Pós-Graduação em Informática na Educação, pág. 137-144.

Neto, S; Santos, H; Santos, W (2015) “ABILSEN: Uma Abordagem para Inclusão do Licenciado em Computação no Ensino Básico”. Em: Workshop de Educação em Computação - WEI, CSBC.

Nunes, D. (2011) "Ciência da Computação na Educação Básica”. Jornal da Ciência. Vol. 02, Ed. 09.

Queiroz, P; Santos, Higor; Rodrigues, Ariane (2016) “ Relato de Experiência no PIBID: Projeto interdisciplinar envolvendo licenciandos em Computação e Pedagogia no Ensino Fundamental", In: Anais do XXII Workshop de Informática na Escola (WIE).

Schön, Donald. (1983) “The reflective practitioner”. London: Basic Books.

Silva, T; Silva, A; Melo, J (2011) "Ensino de Algoritmos a Nível Médio Utilizando Música e Robótica: Uma Abordagem Lúdica"”. In WEI - XIX Workshop de Educação em Computação. Rio Grande do Norte, Brasil.

Sousa, Decíloa. (2013) "Desenvolvendo a Lógica e Algoritmos no Ensino Médio", Em: XIX WIE - Workshop de Informática na Escola. Campinas, SP, Brasil. 